\title{
THE SAFETY OF BUILDING STRUCTURES SUBJECT TO UNUSUAL NATURAL AND MAN-MADE DISASTERS
}

\author{
Nguyen Van Pho* \\ Hanoi University of Civil Engineering (HUCE), Vietnam
}

Nguyen Dinh Xan

Danang University, Vietnam

Received 23 November 2006

\begin{abstract}
Previously, we often use the statistical data on natural disasters and mathematical tools such as probabilistic theory, mathematical statistics and random processes to express and analyze natural disasters' phenomena when dealing with the safety problem of building structures subject to natural disasters. However, due to unusual change of the global climate, natural disasters have changed essentially the intensity, frequency and the appearing time so we cannot rely on the statistical data on natural disasters in the past to do that. Therefore, renovation of the thought on selection of plans, calculation, design, and evaluation of safety of building structures to accommodate to natural disasters and man-made disasters is a required task.
\end{abstract}

This paper presents some points of view of the authors, including: (i) Why should we renovate our thought on selection of plans, calculation, design, and evaluation of safety of existing structures? (ii) What are the old thought and the new thought on the safety of building structures? (iii) How to renovate the selection of building plan, calculation, design and evaluation of the safety of building structures? and (iv) How were some building structures in Vietnam decided according to the new thought?

Some specific examples on the selection of building plan given in this paper are to illustrate the authors' opinions.

\section{INTRODUCTION}

According to the statistical data on natural disasters and man-made disasters in the decades at the end of the $20^{\text {th }}$ century and the first years of the $21^{\text {st }}$ century, it is concluded that there have been unusual change of the global climate, resulting in natural disasters that have changed essentially the intensity, frequency and the appearing time.

Developed countries, who used to consider themselves to have enough natural data are now feeling anxious about this.

To talk about man-made disasters, we can see that they often occur in many places of the world, without any rules.

\footnotetext{
*Corresponding author e-mail: vanpho05@yahoo.com.vn
} 
According to the statistical theory, when at least one basic parameter of a system is considerably changed, the statistical data obtained from the system in the period before that event will not be reliable.

Therefore, when dealing with the problem of natural and man-made disasters at present, people seems to fall into the status of information shortage. Generally speaking, we fall into the status of fuzzy information. Fuzzy here means equivocal, uncertain, short of information $[1,2]$.

When stepping into the $21^{\text {st }}$ century, mankind has recognized that many important questions must be dealt with in the undetermined condition of information. This is the cause that makes the theory of decision selection in the undetermined cases brought into the world [3, 4].

Previously, it is enough to use mathematical tools such as probabilistic theory, mathematical statistics and random processes to express and analyze natural disasters' phenomena. However at present, we have to use the fuzzy theory and fuzzy logic $[2,5]$ to do that.

A question that is of global significance in the $21^{\text {st }}$ century is that how can mankind behave sensibly towards natural disasters and man-made disasters?

Today, when dealing with the problem of natural disasters, people conform to the clause as follows:

"At present, the ability of people is not adequate to oppose natural disasters. However, owing to the scientific and technological knowledge, practical experience gained during thousands of years, creativeness and the high accommodation, people should and can, find out the most beneficial mode to coexist with natural disasters".

Therefore, a question arises: how the construction of new building structures and the assessment of the safety of the existing structures can be considered to be sensible in the condition of unusual natural disasters and man-made disasters in the $21^{\text {st }}$ century?

This is an extensive problem that relates to many aspects, including the national strategy of prevention and mitigation of natural disasters that is considered to be the first one, the planning, design, architectural aspect, economy, etc.

In this paper, the author would like to consider some questions, as follows:

- Why should we renovate our thought on selection of plans, calculation, design, and evaluation of safety of existing structures?

- What are the old thought and the new thought on the safety of building structures?

- How to renovate the selection of building plan, calculation, design and evaluation of the safety of building structures?

- How were some building structures in Vietnam decided according to the new thought?

\section{WHY SHOULD WE RENOVATE OUR THOUGHT ON SELECTION OF PLAN, CALCULATION, DESIGN, AND EVALUATION OF SAFETY OF BUILDING STRUCTURES?}

From the past up to now, as a rule, to select the building plan and to determine the loads, we often rely on statistical data and the natural conditions taken place about tens of years or hundreds of years before and rely on the experience accumulated by people during construction and operation of building structures (actually, experience is also the conclusion that is gained from statistical data). This way is adequate in the condition that the external actions on the building is stable during the period prior to and after the construction of the building. As far as we know, in the stable condition, the series of statistical data present the nature of the system. 
Today, there are basic changes in the global natural and social condition. At present we cannot say which rule according to that the natural disasters and man-made disasters occur in the $21^{\text {st }}$ century. We can only know that they take place unusually in terms of both time and intensity and their characteristics are uncertain, equivocal, unclear, e.g. they own themselves with a fuzzy characteristic that is very clear. However, we still have to construct more new buildings and the existing ones have to exist for tens of years or even hundreds of years more! If don't renovate our thought, we may suffer a severe damage due to natural disasters.

Therefore, renovation of the thought on selection of plans, calculation, design, and evaluation of safety of building structures to accommodate to natural disasters and man-made disasters is a required task.

\section{THE OLD THOUGHT ON THE SAFETY OF BUILDING STRUCTURES}

From the past up to now, buildings are considered not to be absolutely safe. However, because people can understand the natural rules, so they can construct buildings that are safe at a required level, so they believe that "the building will be safe during its operation". Thus, the measure for prevention of occurrence and the assessment of damage when the occurrence takes place are not paid much attention to.

According to ISO 2394 [6] and the United standard for design according to reliability - JB 5015392 (China) [7], the reliability index of reinforced concrete residential buildings is: $3.6 \leq \beta$ $\leq 4.2$.

And the corresponding occurrence probability is: $0.00001335 \leq \mathrm{P}_{\mathrm{f}} \leq 0.0006871$.

According to [8], in the USA, atomic power plants are allowed to be designed with the velocity of a tornado whose occurring probability is $10^{-7}$.

The old thought on the safety of building structures can be summarized as follows:

Based on the data observed and measured during the past on the natural conditions, standard loads for each type of buildings were selected. The construction and operation process of the building were supposed to be taken place in an ordinary condition. Of course, the errors, tolerances, defects, could not be avoided during the design, fabrication, construction and operation. To compensate these, the coefficients that are $>1$ (if they are the multipliers) and the coefficients that are $<1$ (if they are the factors of the dividend) are specified in the design standards.

Because the occurrence probability of the building specified in the design standard is small enough (the seldom event), when the Engineer designs the building according to the specified standard, he believes in the safety of the building, without knowing that even in the ordinary natural condition, the building's safety (designed according to specified standard) is also limited and, the situation would be worse in the unusual natural condition when the potential occurrence cannot be forecasted!

There are three aspects of the old thought that are not suitable for the new situation:

- Arguments and calculations are usually based on social and natural statistical data in the ordinary natural condition, without considering the unusual natural conditions;

- By believing in the safety of the building, the Designers may pay no attention or due attention to the prevention of occurrence and evaluation of the level of damage to the building when appearing the occurrence to answer the question: the would-be occurrence is accepted or not?

- The mathematical tools are probabilistic theory, mathematical statistics and random process 
theory. They are not sufficient for dealing with the problems relating to fuzzy information.

\section{NEW THOUGHT ON SELECTION OF BUILDING PLAN, CALCULATION, DESIGN, AND EVALUATION OF THE SAFETY OF EXISTING BUILDING STRUCTURES}

In the condition of unusual loads and actions whose rules cannot be forecasted, the person who selects the building plan has to accept an occurrence, but the occurrence must be "the acceptable occurrence". If the occurrence is "the unacceptable occurrence" another plan must be chosen.

"The acceptable occurrence" is the occurrence that may cause loss of people, property and damage to the environment but, at a given level and the consequences can be restored after a given period, without accompanying any significant and long-term disasters on politics, economy, society and environment, etc.

The definition of what "the acceptable occurrence" and "the unacceptable occurrence" are depends on the specific economic and social condition of each region. The classification of occurrences should consult the authorized bodies (the local authority). The opinions of the scientists should be regarded as the consulting advices.

To evaluate the safety of the building in unusual natural condition, fuzzy analyzing theory should be applied. Due to this reason, the current design standards should also be modified and supplemented.

The new thought on the safety of the building contains the following noticeable points:

- Though the Designers have tried to design the building with a given safety, but we have to accept the occurrence that may occur due to the unusual action of natural disasters and manmade disasters;

- The calculation and evaluation of loads and actions, in both situations, ordinary and unusual, are conducted;

- Damage to the building due to the would-be occurrence with different level of loads is evaluated to answer the question: the occurrence is accepted or not;

- The prevention and mitigation of damage due to natural disasters are considered (structural and non-structural measures). These help to determine whether the would-be occurrence is accepted or not.

- In addition to mathematical tools such as probabilistic theory, mathematical statistics and random process theory, we have to apply fuzzy sets theory and fuzzy logic [2, 9]. Knowledge on structural mechanics can also be applied but, with an adequate modification and supplement.

From the new thought on the safety of the building mentioned above, many questions on construction of buildings should be changed. For example:

- The building plan should be chosen in such a way that can mitigate damage caused by natural disasters. If the occurrence happens, it should be "the acceptable occurrence";

- The Designer should choose adequate design parameters (including ordinary and unusual loads);

- To analyze the building, both traditional method and fuzzy analyzing method $[9,15,16]$ should be applied;

There might be opinions saying that the above considerations have nothing new, just "the old alcohol in the new vase" because the above matters have been considered when dealing with 298 
important and particularly important building structures. That is partially right. With regard to important and particularly important building structures, the unusual factors of the weather used to be paid attention to when selecting the building plan but, these were the qualitative analysis, rather than the quantitative one that should be taken into account in the required calculation procedure.

On the other hand, in the actual situation of construction, due to the thinking of "believing in the safety", to increase the safety of the building, the Designer has increased the Reliability $[10,11]$. However, the building is not ensured of safety though its reliability was increased when the unusual circumstance takes place.

To prove that different thoughts will result in different conclusions, hereinafter the Author would like to express the decisions made according to the above new thought with regard to some building structures that have been, being or will be constructed in Vietnam.

\section{SOME STRUCTURES IN VIETNAM WHOSE LOTS WERE DECIDED ACCORDING TO THE NEW THOUGHT}

\subsection{The dam of Son La hydraulic power plant (Son La province, North of Vietnam) [13]}

The dam of Son La hydraulic power plant is now being constructed and many matters relating to the Son La hydraulic power plant are not intended by the Author to present in this paper. Hereinafter, the Author would like to present an aspect that relates to "new thought on selection of building plan", which has been approved by Vietnam Government.

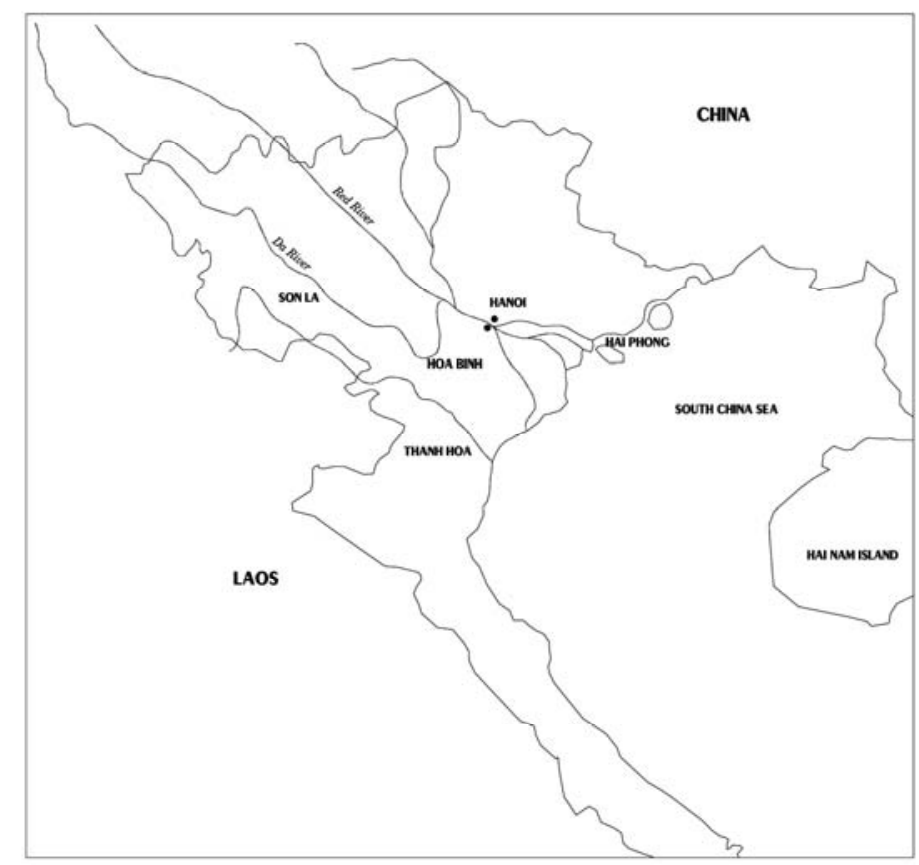

Fig. 1: The Son La hydraulic power plant and Hanoi

For a long time, many professional scientists and construction managers have contributed their opinions to the selection of the building plan for the Son La hydraulic power plant requested by the Vietnam Government. There were two building plans: high-Son La hydraulic power plant 
(265 m) and low-Son La hydraulic power plant (215 m). The above opinions have been issued on the media. The Vietnam National Assembly and Government have also discussed much this matter because Son La hydraulic power plant is a particularly important structure and the absolute safety for Hanoi, the capital of Vietnam, must be ensured.

Based on the observed and monitored data for the past many years on rainfall, flooding, earthquakes and water level on rivers, some seismologists and large-dam construction experts have determined that the plan of high-Son La hydraulic power plant (265 $\mathrm{m}$ ) be selected because the structural solution to ensure the absolute safety for Hanoi is feasible.

At the same time, some other scientists involved in structural engineering field have believed that due to the unusual characteristics of natural disasters and man-made disasters in the $21^{\text {st }}$ century, the seismic and flooding data in the $20^{\text {th }}$ century were not reliable to select the building plan in the $21^{\text {st }}$ century. They have quoted the following issues:

- The Son La hydraulic power plant is located in the upper reaches of the Red river while Hanoi is located in the lower reaches of the Red river. If the occurrence happens to the Dam of Son La hydraulic power plant, a large area of the Red river delta (North of Vietnam), including Hanoi, would be flooded. To avoid flooding, people have built the river dykes (the dykes that run along the river banks) and build some flooding sharing structures (e.g. drainage sewers under the dykes. When required, some pre-determined segments of the dyke at suitable locations may be purposely destroyed to open the way for flooding water) to reduce the water level at the river segment going through Hanoi. However, what is the maximum flooding water level can the above rive dyke system and the flooding sharing measure resist ? With the unusual disasters as we often see, how could we ensure that there would not be a flooding that was stronger than the flooding the river dyke system can resist?

- If the occurrence happens, how is the damage ? and is the damage accepted?

- Is there any measures for prevention and mitigation of damage due to natural disasters?

- Is that a disaster (the man-made one) if a huge amount of water more than 30bil. $\mathrm{m}^{3}$ "hangs" over Hanoi?

- There is no reason why Vietnam is now in the active situation and "would like to be" in passive situation to man-made and natural disasters?

How do the natural disasters and man-made disasters behave in the $21^{\text {st }}$ century? This is a problem that is questionable. On the basis of this judgment, the Vietnam Government has decided to select the building plan of low-Son La hydraulic power plant (215 m) to ensure the required safety for Hanoi and with this plan, the occurrence, if unfortunately happens, would be "the acceptable occurrence".

\subsection{Transformation plan for a segment of Red river that goes through Hanoi [12]}

Hanoi is located on the two banks of the Red river. Owing to the river dyke system, when flooding water rises, Hanoi is still safe if the river water has not overflowed the dyke or the dyke is still stable under the action of flooding.

When transforming a segment of Red river that goes through Hanoi, there are two important noticeable tasks:

- How to regulate properly the river flow? and

- How to use reasonably the land areas inside the dykes and along the river banks?

Based on the statistical data on flooding and water flows in many past years, the authority in charge has forecasted the erosion and flow velocity at the land areas inside the dykes and along 
the river banks and judged that in the concave areas inside the dykes and along the river banks, the flooding water velocity is low so these areas do not make a great contribution to the flooding drainage. Therefore, permanent multi-story buildings are allowed to be built in these areas.

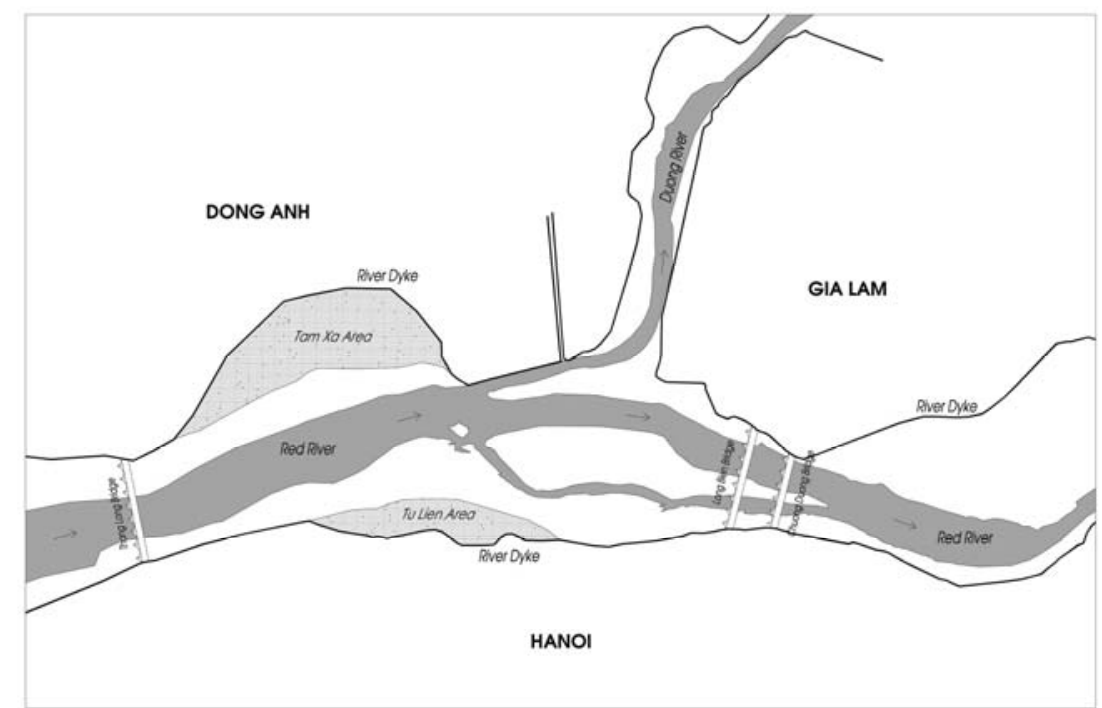

Fig. 2: The rive dyke system and the Red river segment that runs through Hanoi

As a result, the authority has relied on the statistical data monitored in the $20^{\text {th }}$ century to decide the matters that take place in the $21^{\text {st }}$ century. This is not sensible.

To have a sensible decision, the following matters should be considered:

- With regard to the unusual big flooding, the river dyke system that protects Hanoi cannot resist;

- Hanoi's people would not like to leave the low areas for the upper ones that are not flooded because they have got used to live in Hanoi for nearly 1,000 years;

- To maximize the water flow of the Red river segment, which goes through Hanoi, the regulation of Red river flow and deletion of the so-called "narrowed necks slots" should be carried out. If required, the regulation of locations of some dyke segments should be accepted.

- It is required to calculate the water flow according to the created flooding drainage gallery for forecasting the occurrence and for determining which areas inside the dyke system do not make a significant contribution to the flooding drainage. In these areas, building structures are allowed to be built. In the areas that belong to the flooding drainage gallery, only the farming activities are allowed.

- The expanding of Hanoi should be carried out in the Northern and North-western directions, which are the non-flooding regions.

- A long-term strategy on prevention and mitigation of natural disasters for Hanoi and the Red river delta should be considered.

\subsection{Selection of building plan for coastal industrial zones}

In Vietnam, there are many industrial zones built in the coastal area because these areas are rare 
to be flooded due to raining water coming from the row of Western mountains. However, they often suffer from strong typhoons and risen sea water due to big waves.

Therefore, to make use of coastal land, in some places, sea dyke systems have been built.

Let's take the Amura industrial Zone (Hai phong city) as an example. It is located in the coastal area of Port city of Hai phong (North of Vietnam), which has a $10 \mathrm{~km}$ of sea dyke system. According to the statistical date, if the sea dyke system is not available, on the average, this area will be flooded with a frequency of one time per 7 - 10 years. However, when the sea dyke system is present, on the average, the dyke would be broken down one time per 30 years.

The sea dyke system is rather long and costly. So the height of the sea dyke is limited and, of course, we have to accept the occurrence (on the average, the occurrence happens one time per 30 years) and apply two measures at the same time:

- Annually strengthening the sea dyke system; and

- Prevention of sea water overflowing due to the breakdown of the dyke, by building at least two-story buildings. The cladding system of the first floor is not required to be durable when it is subject to sea waves while is the frame. The cladding system of the first floor should be broken down so as not to obstruct the sea waves. On the contrary, the cladding system of the $2^{\text {nd }}$ and $3^{\text {rd }}$ floors should be durable for sheltering people and costly machinery and equipment.

As a result, people accept damages when the occurrence happens and agree to select appropriate measure to mitigate damages due to natural disasters. Other matters relating to industrial zones are not presented here.

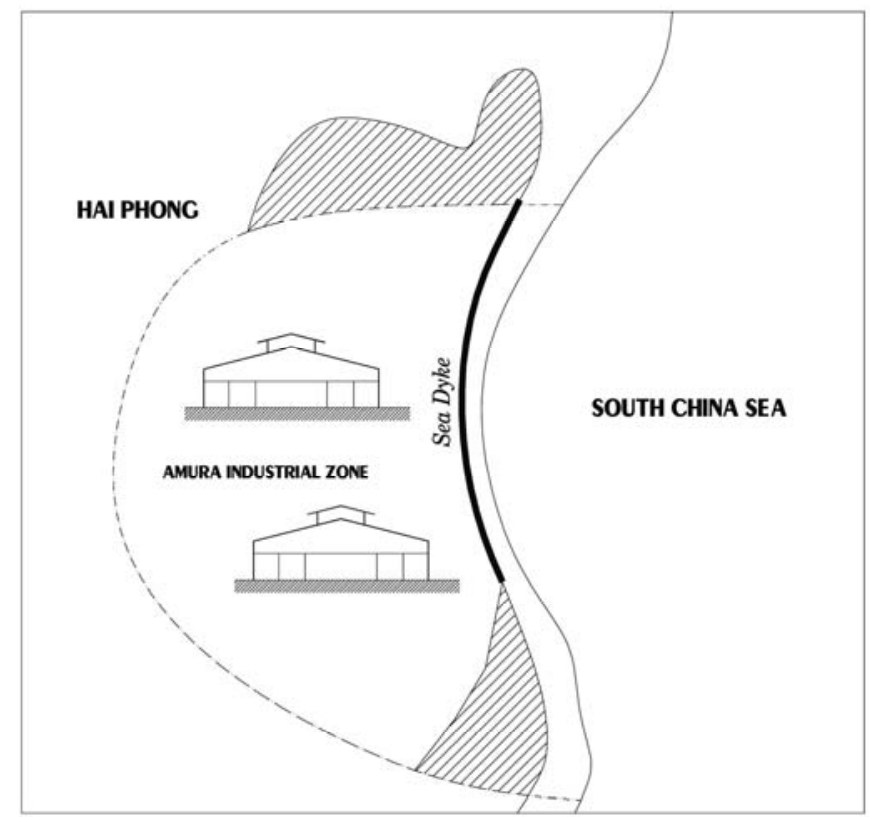

Fig. 3: Location of the Amura Industrial Zone

\subsection{Multi-purpose residential buildings on coastal area for habitation in ordinary condition and for sheltering in case of natural disasters}

Vietnam has more than 3,000 km of coastal bank in the East in which there are many beaches and touring areas. However, these areas often suffer from typhoons and strong winds. 
Therefore, the proposed question is how to build populated areas along the coastal area to exploit well the income sources from the sea as well as to ensure the safety of life and property of inhabitants when natural disasters occur.

Because, the cost to build all the strong buildings (which are firm and can resist typhoons) is not enough, in the groups of populated areas, people often build some strong buildings. In the ordinary natural condition, these buildings can be used as offices, schools or business centers. In case of natural disasters, these buildings can be used as the shelters for inhabitants. The building model may be multi-story buildings but the safety of the available floors are not the same. The first, second and third floors (or the second and third floors) may be firmly designed, i.e. these floors can be used as shelters in case of natural disaster. The upper floors may be weakly designed and they might be collapsed due to natural disasters. This means that damage is accepted provided that the life is safe.

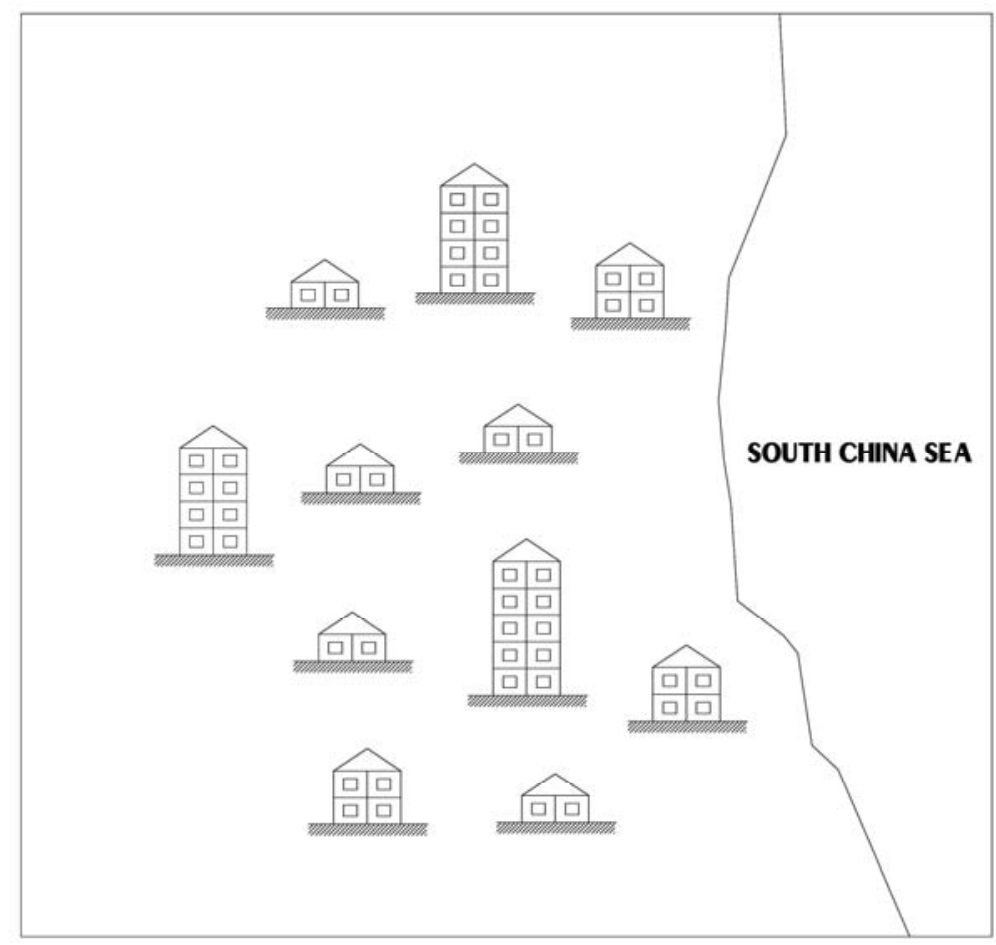

Fig. 4: Low and multi-story buildings are situated together in the coastal residential area

\subsection{Building typhoon-resistant vaults}

In the typhoon Shansane that took place on October 2006, people in some regions of Vietnam have proofed against the typhoon by building underground, semi-underground vaults or aboveground vaults. Typhoon resistant vaults are the safe places during the typhoon. The vault is still safe in case of building's collapse. The vault may be built inside or outside the building. When there is no typhoon, the vault can be used as the store for preservation of the property. When natural disasters appear, it becomes the shelter. The vault should be a firm structure. It may be a house room or a portion of a house room, depending on the available financial condition. The vault should not be built in flooding prone places.

It is seen, from the above examples, that the new thought on the safety of the building considerably influences on the selection of building plans. 


\section{CALCULATION, DESIGN, AND EVALUATION OF SAFETY OF EXISTING BUILDING STRUCTURES}

After the building plan is determined, technically, the following tasks should be carried out:

- Determination of loads (wind, flooding, earthquake, etc.);

Levels of loads acting on the building should be forecasted. There are two types of loads: usual loads and unusual loads. Usual loads are the loads, which are determined according to the statistical data on the natural condition of many past years. Unusual loads are the loads forecasted for the case of unusual natural disasters. Unusual loads are the fuzzy variables (due to shortage of data).

For example, with regard to the windload at a location of Vietnam, according to the wind pressure zoning map of Vietnam [17], the design windload is determined as $150 \mathrm{~km} / \mathrm{h}$. Another usual windload of $140 \mathrm{~km} / \mathrm{h}$ and other two unusual windloads of $165 \mathrm{~km} / \mathrm{h}$ and $180 \mathrm{~km} / \mathrm{h}$ should also be taken into account.

- Calculation of the reliability according to the levels of loads. With the levels of windloads of $140 \mathrm{~km} / \mathrm{h}$ and $150 \mathrm{~km} / \mathrm{h}$ (usual levels), the reliability is calculated by the familiar methods [10, $11,14]$. With regard to unusual levels of windloads of $165 \mathrm{~km} / \mathrm{h}$ and $180 \mathrm{~km} / \mathrm{h}$, we have to analyze fuzzy reliability $[9,15,18,19]$

- Calculation of cost estimation for each situation;

- Combination of related factors to find out the most appropriate design plan;

Evaluation of the safety of existing building structures shall be carried out in the same way.

\section{CONCLUSION}

In this paper, the author has mentioned only the principled questions on the renovation of the thought in constructing building structures subject to the action by unusual natural disasters. The renovation of thought will result in the required renovation of many steps (stages) that have to be performed during the construction of building structures such as: selection of building site, calculation, design, evaluation of the safety of existing building structures, etc.

The specific examples on selection of building plan given in this paper are to illustrate the Author's arguments only. In practice, the final plan shall be decided according to the specific condition of each region, each country.

To prevent and mitigate damage to building structures by natural disasters, structural and nonstructural measures should be combined. By combining these two measures, Vietnam has achieved significant success in mitigating damage, particularly loss of life, due to the typhoon Shansane, which landed in Middle provinces of Vietnam on October 2006.

Structural measures appropriate for the case of unusual natural disasters have not been studied yet and, there are very few studies on the reliability of buildings in case of fuzzy information [9, $13,15,20]$.

The opinions given in this paper are only the initial opinions on an extensive and complicated problem that has a great applying prospect. Therefore, the Author would like to receive the exchange of opinions from the concerned colleagues according to the following e-mail: vanpho05@yahoo.com.vn. 


\section{ACKNOWLEDGEMENT}

This paper is completed with the financial assistance from the "Basic research programme in Natural science fields (Mechanical discipline)". The Author would like to thank to Ministry of Science and Technology of Vietnam and the chairing board of the Basic research programme in Natural science fields.

\section{REFERENCES}

1. Zadeh, L.A. (1965), Fyzzy sets. Information and Control, 8/1965.

2. Zimmermann, H.J. (1991), Fyzzy sets and its Application, 2nd Ed. Kluwer Acad. Pub.

3. Nguyen Van Pho (2003), Application of the theory "selection of decision in the undetermined cases" to the evaluation of occurrences of buildings due to natural disasters. Proceedings of the $2^{\text {nd }}$ National Scientific Conference on Occurrence and Damage to Building structures, Hanoi, 12/2003.

4. Bui Cong Cuong (2001), Fuzzy systems, neuron net and application. Scientific and Technical Pub. House, Hanoi.

5. Nguyen Van Pho (2001), Mechanics in the condition of fuzzy information. Proceedings of the $5^{\text {th }}$ National Scientific Conference on Solid Mechanics. Do Son, Haiphong, 8/2001.

6. International Standard ISO 2394-1998. General principles on Reliability of Structures.

7. United standard for design according to reliability, JB 5015392 - Standard of the People's Republic of China (in Chinese).

8. Simiu, E. and Scanlan, R.H. (1986), Wind effects on Structures (Seemd Edition). John Wiley and Sons.

9. Bernd Moller and Michael Beer (2004), Fuzzy Randomness. Uncertainty in Civil Engineering and Computational Mechanics. Springer.

10. Bolotin, V.V. (1965), Statistical Methods in Structural Mechanics. Moscow (in Russian).

11. Achintya Haldar (2000), Probability, Reliability and Statistical Methods in Engineering Design. John Wiley and Sons.

12. Nguyen Van Pho (2004), Hanoi - some questions that should be paid attention to during the construction and development. Hanoi - 50 years of achievements and challenges in the development way. National political Pub. House, Hanoi.

13. Nguyen Van Pho (2005), A new approach to the selection of plan for constructing structures, taking into account of potential occurrence caused by natural disasters. Proceedings of the $3^{\text {rd }}$ National Scientific Conference on Occurrence and Damage to Building structures, Hanoi, 11/2005.

14. Palle Thoft - Christensen and Yoshisada Murotsu (1986), Application of Structural Systems Reliability Theory. Springer - Verlag. Berlin Heidelberg - New York - Tokyo.

15. Nguyen Van Pho, Nguyen Dinh Xan, and Nguyen Thac Vu (2005), A method for calculation of reliability of buildings with the participation of fuzzy variables. Journal of Building Science and Technology, Institute for Building Science and Technology (IBST), $\mathrm{N}^{0} .3 / 2005$.

16. Nguyen Van Pho (2005), The general Interference Model in the Fuzzy Reliability Analysis of systems. Vietnam Journal for Mechanics, $N^{0}$. 5/2005. 
17. Vietnam standard TCVN 2737-1995: Loads and Actions - Design Norm.

18. Hong, H.P. (2000), Assessment of Reliability of Aging Reinforced concrete structures. 1458, Journal of Structural Engineering.

19. Anoop, M.B., Rao, K.B., and Rao, T.V.S.R.A. (2002), Application of fuzzy sets for estimating service life of reinforced concrete structural member in Corrosive environments. Engineering structures 24.

20. Nguyen Dinh Xan (2006), Assessment of reliability of structural members in case of fuzzy data. PhD. thesis, Hanoi University of Civil Engineering, 3/2006. 